\title{
Pretreatment of Crumb Rubber with a Silane Coupling Agent to Improve Asphalt Rubber Performance
}

\author{
Li Liu $\mathbb{D}^{1,2}$ Zhaohui Liu, ${ }^{2}$ and Chengcheng Yang ${ }^{2}$ \\ ${ }^{1}$ National Engineering Laboratory for Highway Maintenance Technology, School of Traffic and Transportation Engineering, \\ Changsha University of Science \& Technology, Changsha 410114, China \\ ${ }^{2}$ School of Traffic and Transportation Engineering, Changsha University of Science \& Technology, Changsha 410114, China
}

Correspondence should be addressed to Li Liu; 805296712@qq.com

Received 12 June 2021; Revised 22 September 2021; Accepted 23 September 2021; Published 12 October 2021

Academic Editor: Rotana Hay

Copyright (c) $2021 \mathrm{Li} \mathrm{Liu} \mathrm{et} \mathrm{al.} \mathrm{This} \mathrm{is} \mathrm{an} \mathrm{open} \mathrm{access} \mathrm{article} \mathrm{distributed} \mathrm{under} \mathrm{the} \mathrm{Creative} \mathrm{Commons} \mathrm{Attribution} \mathrm{License,} \mathrm{which}$ permits unrestricted use, distribution, and reproduction in any medium, provided the original work is properly cited.

\begin{abstract}
There are known problems of dissolution, consistency of performance, segregation, and instability with the crumb rubber currently used in asphalt for road engineering. A silane coupling agent (KH550) solution was therefore used to pretreat the crumb rubber so as to improve its interfacial characteristics. The effects of KH550 on the properties of asphalt rubber were studied using high- and low-temperature performance tests, temperature sensitivity test, and compatibility test. On the basis of these tests, the optimum concentration of KH550 pretreated crumb rubber is $1.0 \%$. The surface properties and micromodifications of the treated crumb rubber were analyzed using scanning electron microscopy and an infrared spectrometer. The performance and economic benefit of the modified asphalt rubber was compared to styrene-butadiene-styrene (SBS) modified asphalt, and it was found that KH550 pretreated crumb rubber is able to significantly improve the high-temperature performance of asphalt rubber, thus offering notable potential economic benefits.
\end{abstract}

\section{Introduction}

In recent years, a growing concern with saving energy, reducing emissions, recycling, and environmental protection has led to a stronger emphasis upon environmentally and socially responsible highway construction, encapsulated in the idea of the "Green Highway" and the work of the Green Highways Partnership (GHP), which is dedicated to transforming the relationship between the environment and transportation infrastructure.

Waste tires were once considered "black pollution," which are not only damaging to the environment, but also a waste of resources [1-3]. Developments in industry have made it possible to turn waste tires into crumb rubber for highway engineering. This not only deals with the black pollution problem in a "one-step" and harmless way but also improves the quality of asphalt pavements and prolongs their service life [4-6].

Asphalt rubber has been applied in road engineering for nearly 50 years. It is widely used in the production of asphalt rubber concrete, stress absorbing layers (Sam), stress absorbing intermediate layers (Sami), crushed stone seals (CHIP SEAL), waterproof pavement materials (TRCK COAT), and filling materials. Years of research and engineering practice have underscored the obvious advantages of asphalt rubber concrete in reducing road noise, delaying reflection cracks, and reducing the thickness of asphalt pavements and resistance to heavy traffic and bad weather $[7,8]$.

Crumb rubber is a macromolecular compound and its preparation and use in asphalt rubber involves a complex physical-chemical reaction with asphalt. It is difficult to completely dissolve crumb rubber in the asphalt matrix, making it easy for segregation to occur during transportation and use and diminishing the quality of asphalt rubber pavements [9-11].

While crumb rubber is an organic compound, asphalt is a mixture containing organic and inorganic compounds. The molecular structure of the silane coupling agent, KH550, can act as a "molecular bridge" in the form of $\mathrm{Y}-\mathrm{R}-\mathrm{Si}(\mathrm{OR})_{3}$, in 
which $\mathrm{Y}$ is an organic functional group and $\mathrm{Si}(\mathrm{OR})_{3}$ is a siloxane group. The siloxane group can react with the inorganic compounds, and the organic functional group can react with the organic compounds. When KH550 is interposed between the inorganic and organic interfaces, an organic matrix-silane coupling agent-inorganic matrix combination can be formed. Thus, the crumb rubber and the asphalt can be connected using the silane coupling agent to promote their mutual compatibility and effectively improve the road performance of the asphalt rubber [12-15].

This paper reports on a study of the technology involved in pretreating the surface of crumb rubber with the silane coupling agent, $\mathrm{KH} 550$, and the subsequent process of preparing asphalt rubber. The high-temperature performance, low-temperature performance, temperature sensitivity, and segregation performance of asphalt rubber before and after the addition of KH550 pretreated crumb rubber are compared and analyzed, and the optimum concentration of KH550 pretreated crumb rubber is determined. The mechanism by which crumb rubber pretreated with KH550 is modified is revealed and discussed through the use of scanning electron microscopy and an infrared spectrum test. The performance and economic benefit of using this kind of asphalt rubber is compared with that of SBS modified asphalt [16-19].

\section{Materials and Methods}

2.1. Materials. The base asphalt used in our tests was $70^{\#}$ asphalt and its performance indices are shown in Table 1. The molecular formula of $\mathrm{KH} 550$ is $\mathrm{NH}_{2}\left(\mathrm{CH}_{2}\right)_{3} \mathrm{Si}\left(\mathrm{OC}_{2} \mathrm{H}_{5}\right)_{3}$, wherein $\mathrm{NH}_{2}\left(\mathrm{CH}_{2}\right)_{3}$ - is an organic functional group and $-\left(\mathrm{OC}_{2} \mathrm{H}_{5}\right)_{3}$ is a siloxy group. Its physical properties (provided by the manufacturer) are shown in Table 2 . The particle size of the crumb rubber was 40 mesh, and its performance indices are shown in Table 3.

\subsection{Technology for Pretreating Crumb Rubber with KH550.} KH550 was added to an ethanol solution prepared with $\mathrm{m}$ (water) : $\mathrm{m}$ (anhydrous ethanol) $=1: 20$, where the different concentrations of $\mathrm{KH} 550$ at room temperature were $0.7 \%, 1.0 \%$, and $1.3 \%$. The three different concentrations of KH550 were used to treat crumb rubber by adding them to the crumb rubber in a solid blender. The rotational speed of the solid blender was $200 \mathrm{r} / \mathrm{min}$, and the treatment was conducted for $30 \mathrm{~min}$. As crumb rubber is granular and has a large specific surface area, the treatment time was controlled at about $30 \mathrm{~min}$ to ensure there was enough time for it to react fully with the KH550 solution. The treated crumb rubber was dried in an oven at about $100^{\circ} \mathrm{C}$. The standard used to assess when the drying was complete was that the crumb rubber modifier was able to be completely dispersed without agglomeration, and after weighing separately for two times, the weight difference was less than $0.1 \%$. Adding crumb rubber modifier that has not completely dried into asphalt can result in a large number of bubbles and may even lead to the asphalt rubber swelling and overflowing because of the presence of ethanol and water. Once this process was complete, the asphalt rubber could be prepared by adding the crumb rubber modifier. For the sake of convenience, the asphalt rubber incorporating the crumb rubber modifier after surface treatment will be called "modified asphalt rubber" from now on. The process flow for pretreating CRM with KH550 solution is shown in Figure 1.

2.3. Preparation of the Modified Asphalt Rubber. With the drying of the crumb rubber modifier complete, the matrix asphalt was heated to $170 \sim 180^{\circ} \mathrm{C}$ in an oven and kept at constant temperature for about $1 \mathrm{~h}$. Then, the weighed crumb rubber modifier was added and the mixture was sheared for $30 \mathrm{~min}$ at $5000 \mathrm{r} / \mathrm{min}$ using a high-speed shearing apparatus. After this, the mixture was put back into the oven at $170 \sim 180^{\circ} \mathrm{C}$ for $30 \mathrm{~min}$. Finally, the developed mixture was sheared again for $15 \sim 20 \mathrm{~min}$ at $5000 \mathrm{r} / \mathrm{min}$ and then was allowed to swell for $1 \mathrm{~h}$. When this process finished, the modified asphalt rubber was ready for testing. The process of preparing the modified asphalt rubber is shown in Figure 2.

2.4. High-Temperature Performance Test. The high-temperature performance of asphalt is directly related to the resistance of an asphalt pavement to deformation under temperature and load. In this paper, a softening point test and DSR complex shear viscosity test were used to evaluate the high-temperature performance of the modified asphalt rubber. The softening point of two kinds of asphalt rubber was measured by an automatic softening point meter. A dynamic shear rheometer (DSR) was used to measure the viscosity of the two kinds of asphalt rubber at $50 \sim 175^{\circ} \mathrm{C}$. Their complex shear viscosities at $60^{\circ} \mathrm{C}$ were used as evaluation indexes. Both specimens had a diameter of $25 \mathrm{~mm}$ and a thickness of $1 \mathrm{~mm}$. The test frequency was $10 \mathrm{rad} / \mathrm{s}$, in accordance with AASHTO T315-05 [20].

2.5. Low-Temperature Performance Test. Low temperatures are one of the most important causes of the cracking of asphalt pavements, so the low-temperature performance of the asphalt directly affects a pavement's resistance to cold conditions. Low-temperature ductility tests and low-temperature bending beam rheological tests were therefore used to evaluate the low-temperature performance of the modified asphalt rubber. The $5^{\circ} \mathrm{C}$ ductility of the two kinds of asphalt rubber was measured by an automatic ductility tester. The values for the creep stiffness modulus, $S$, and creep rate, $m$, were measured at $-6^{\circ} \mathrm{C}$ by a low-temperature bending beam rheometer (BBR). The size of the specimens was $6.25 \mathrm{~mm}^{\mathrm{H}} \times 12.5 \mathrm{~mm}^{\mathrm{W}} \times 127 \mathrm{~mm}^{\mathrm{L}}$, and the specimens were loaded at $980 \mathrm{mN} \pm 50 \mathrm{mN}$ for $240 \mathrm{~s}$, in accordance with AASHTO T313-12 [21].

2.6. Temperature Sensitivity Test. Asphalt is a temperaturesensitive material. Its temperature sensitivity is an important indicator for determining its workability and serviceability on the road surface. In this paper, we have used a penetration 
TABle 1: Performance indices of $70^{\#}$ asphalt.

\begin{tabular}{|c|c|c|c|}
\hline Design index & & Unit & Detected result \\
\hline Penetration $\left(25^{\circ} \mathrm{C}, 100 \mathrm{~g}, 5 \mathrm{~s}\right)$ & & $0.1 \mathrm{~mm}$ & 70 \\
\hline Penetration index PI & & - & -0.87 \\
\hline Softening point $R$ and $\mathrm{B}$ & & ${ }^{\circ} \mathrm{C}$ & 49 \\
\hline Dynamic viscosity $\left(60^{\circ} \mathrm{C}\right)$ & & Pa.s & 230 \\
\hline Ductility $\left(10^{\circ} \mathrm{C}, 5 \mathrm{~cm} / \mathrm{min}\right)$ & & $\mathrm{cm}$ & 37 \\
\hline Ductility $\left(15^{\circ} \mathrm{C}, 5 \mathrm{~cm} / \mathrm{min}\right)$ & & $\mathrm{cm}$ & $>100$ \\
\hline Density & & $\mathrm{g} / \mathrm{cm}^{3}$ & 1.040 \\
\hline \multirow{3}{*}{ Aging of rotating thin films (RTFOT) } & Mass loss & $\%$ & -0.328 \\
\hline & Ductility $\left(10^{\circ} \mathrm{C}, 5 \mathrm{~cm} / \mathrm{min}\right)$ & $\mathrm{cm}$ & 6.2 \\
\hline & Penetration ratio & $\%$ & 63.8 \\
\hline
\end{tabular}

TABle 2: Physical properties of KH550.

\begin{tabular}{lc}
\hline Item & Property \\
\hline Appearance & Colorless transparent liquid \\
Proportion $\left(25^{\circ} \mathrm{C} / 25^{\circ} \mathrm{C}\right)$ & 0.946 \\
Boiling point $/{ }^{\circ} \mathrm{C}$ & 217 \\
$n_{\mathrm{D}}{ }^{25}$ & 1.420 \\
Solubility & Water-soluble \\
Acid-base property & Alkalinity \\
\hline
\end{tabular}

TABLe 3: 40-mesh crumb rubber performance indices.

\begin{tabular}{lccc}
\hline Technical index & Detected result & Technical index (\%) & Detected result \\
\hline Relative density & 1.2576 & Acetone extractives & 12.4 \\
Water (\%) & 0.1 & Carbon black content & 34.8 \\
Metal content (\%) & 0.002 & Rubber hydrocarbon content & 48.6 \\
Fiber content (\%) & 0.3 & Ash & 3.1 \\
\hline
\end{tabular}

index to evaluate the temperature sensitivity of the modified asphalt rubber. The penetration index was calculated according to formulas (1) and (2) when testing the penetration of the modified asphalt rubber at $15^{\circ} \mathrm{C}, 25^{\circ} \mathrm{C}$, and $30^{\circ} \mathrm{C}$.

$$
\begin{gathered}
\lg P=K+A \bullet T, \\
\mathrm{PI}=\frac{20-500 A}{1+50 A},
\end{gathered}
$$

where PI is the penetration index; $\lg P$ is the logarithm of the penetration value measured at different temperatures; $T$ is the test temperature; and $K$ and $A$ are regression coefficients.

2.7. Storage Stability Performance Test. As crumb rubber is a polymer material, it needs to undergo high-speed shearing, swelling, and development. However, it is difficult to ensure that it is completely dissolved in the asphalt. This can easily result in segregation during storage and transportation, thus affecting its performance. To evaluate the storage stability properties of the modified asphalt rubber and analyze the compatibility of the crumb rubber with the asphalt, tests were carried out in accordance with JTG E-20-2011, Standard Test Methods of Bitumen and Bituminous Mixtures for Highway Engineering [22]. The specific process was as follows: the two kinds of modified asphalt rubber were heated to ensure they were fully irrigated. After uniform stirring, about $50 \mathrm{~g}$ of the modified asphalt rubber was slowly injected into a vertical aluminum tube. The opening of the tube was then closed with tweezers, and the tube was placed in an oven at $165^{\circ} \mathrm{C} \pm 1^{\circ} \mathrm{C}$ for $48 \mathrm{~h} \pm 1 \mathrm{~h}$. After heating, the aluminum tube was put in a freezer for $4 \mathrm{~h}$ to solidify the asphalt rubber. Then, the tube was cut into three sections with scissors. The upper and lower sections were put into sample boxes and heated until the asphalt rubber had melted. After mixing, the softening point test samples were poured, and their softening point was tested. It was then possible to evaluate the storage stability performance of the modified asphalt rubber by comparing the difference between the upper and lower sample's softening points.

2.8. Scanning Electron Microscopy Test. Scanning electron microscopy is an important tool for studying the micromorphology and microstructure of materials. In order to evaluate the modification effect of KH550 on the crumb rubber and analyze the changes in the crumb rubber micromorphology from before to after its modification, microobservations of the crumb rubber were carried out using scanning electron microscopy equipment. The specific test process was as follows: $2 \mathrm{~g}$ each of the treated and untreated crumb rubber modifier were weighed and placed 


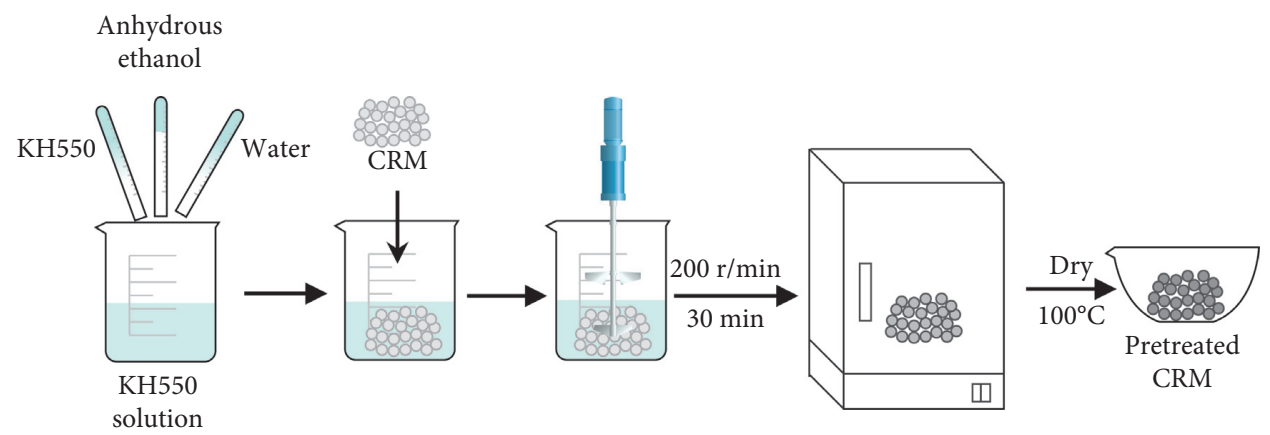

FIgURE 1: The process flow for pretreating CRM with KH550 solution.

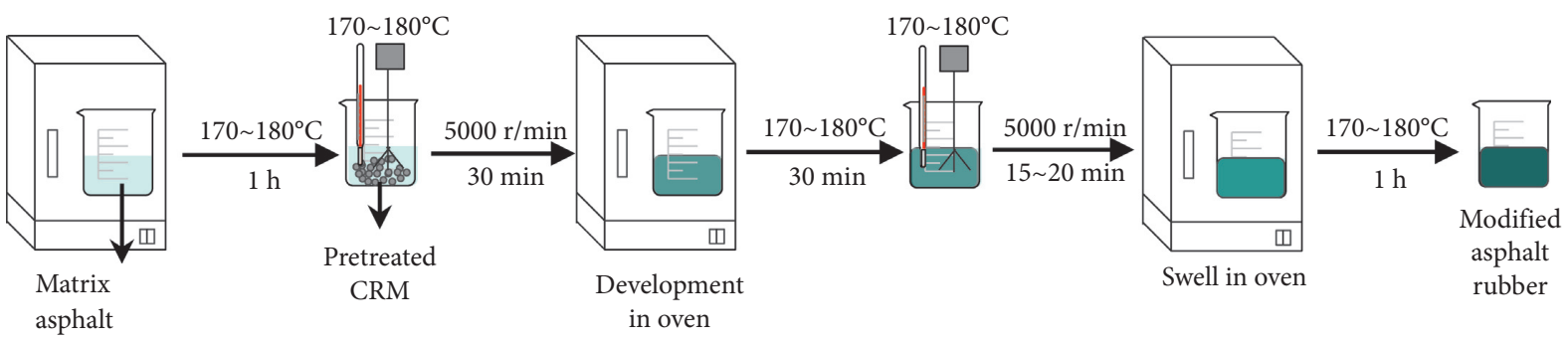

FIGURE 2: The process of preparing the modified asphalt rubber.

on a loading platform. A metal conductive film was evaporated on the surface of each sample using a vacuum membrane plate machine. Then, the loading platform was put into the scanning electron microscopy equipment for testing.

2.9. Infrared Spectrum Test. Infrared spectrum testing provides both a quantitative and qualitative method for analyzing functional group changes in materials. In order to analyze the changes in the asphalt rubber treated with $\mathrm{KH} 550$, it was subjected to infrared spectrum testing. The specific test process was as follows: $1 \mathrm{~g}$ of each of the two kinds of asphalt rubber was weighed and put into a test tube containing a carbon tetra-chloride solution. This was fully stirred until the asphalt rubber had completely dissolved. Two to three drops of the liquid samples were squeezed between two $\mathrm{KBr}$ crystal windows to form a thin liquid film. This was gently clamped with a fixture and put into an infrared spectrometer to determine the spectrogram.

\section{Results and Discussion}

3.1. Test Results of the High-Temperature Performance. The softening points of four kinds of asphalt rubber were tested using a ring and ball method, and the viscosities of the asphalt rubber were measured by a dynamic shear rheometer (DSR). The $60^{\circ} \mathrm{C}$ complex shear viscosities were selected as evaluation indices. The test results are shown in Figure 3.

It can be seen from Figure 3 that as the KH550 concentration increased, the softening point and $60^{\circ} \mathrm{C}$ complex shear viscosity of the modified asphalt rubber also gradually increased, with the growth trend for both being basically the same. This indicates that pretreating the crumb rubber with
KH550 effectively improves the high-temperature performance of asphalt rubber. It specifically suggests that KH550 improves the surface activity of the crumb rubber, enhances its wettability and dispersibility in asphalt, and promotes the compatibility of the crumb rubber and the asphalt.

When the concentration of the KH550 solution was between 0 and $1.0 \%$, the high-temperature performance of the asphalt rubber increased at a continuous rate. However, when the concentration of the KH550 solution was between $1.0 \%$ and $1.3 \%$, the growth rate decreased significantly. This suggests that there is a certain concentration at which a KH550 solution will most effectively treat crumb rubber, with the optimum value being about $1.0 \%$.

3.2. Test Results of the Low-Temperature Performance. Values for the $5^{\circ} \mathrm{C}$ ductility, creep stiffness modulus, $S$, and creep rate, $m$, were acquired using $-6^{\circ} \mathrm{C}$ low-temperature bending beam rheological tests, to evaluate the low-temperature performance of the four kinds of asphalt rubber. As the purpose of these tests was to determine the influence of the KH550 concentration on the performance of the asphalt rubber, the tests were also carried out using unmodified asphalt rubber (asphalt aged without being put in the rotating film oven or subjected to pressure aging). The test results are shown in Table 4.

Table 4 shows that treating crumb rubber with different concentrations of KH550 has little effect on the low-temperature performance of the asphalt rubber. The effect on the $5^{\circ} \mathrm{C}$ ductility was no more than $6.7 \%$, and the effect on the creep modulus $S$ and $m$ values was only $5.6 \%$ and $5.1 \%$. Crumb rubber is an elastic material that reacts with asphalt to enhance its elasticity. However, after the KH550 treatment, the rubber powder is coupled with the asphalt and 


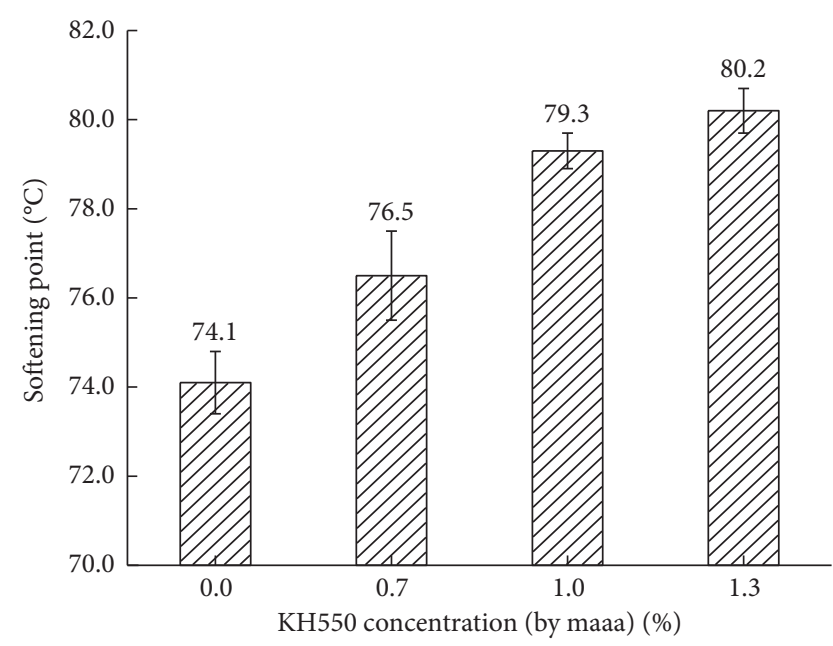

(a)

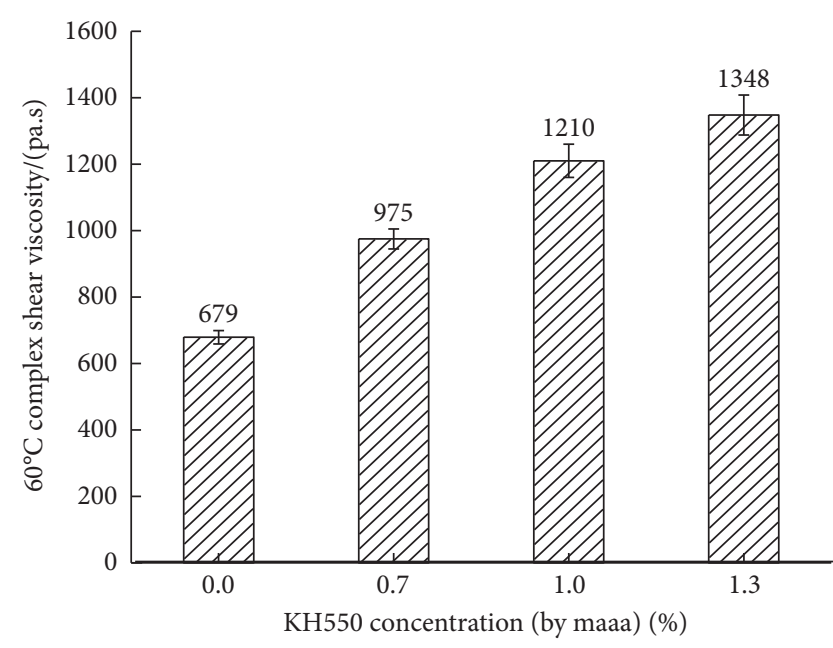

(b)

FIGURE 3: Effect of KH550 concentration on the asphalt rubber's high-temperature performance: (a) softening point; (b) $60^{\circ} \mathrm{C}$ complex shear viscosity.

TABLE 4: Test results of the low-temperature performance of the asphalt rubber.

\begin{tabular}{lcrr}
\hline Modified asphalt rubber & $5^{\circ} \mathrm{C}$ ductility/cm & \multicolumn{1}{c}{$-6^{\circ} \mathrm{C} / \mathrm{MPa}$} & 0.454 \\
\hline $\mathrm{MAR}_{0}$ & 10.3 & 125 & 0.431 \\
$\mathrm{MAR}_{0.7}$ & 10.2 & 131 & 0.443 \\
$\mathrm{MAR}_{1.0}$ & 10.6 & 129 & 132 \\
$\mathrm{MAR}_{1.3}$ & 11.0 & 132 & 0.448 \\
\hline
\end{tabular}

other complex reactions occur, the crumb rubber absorbs the lighter components of the asphalt to produce swelling, penetrating into the asphalt to form a gel layer, but at the same time, the lighter components of the asphalt are reduced, the deformation capacity of low temperature is weakened, and the low-temperature performance of asphalt rubber appears slightly reduced. However, after treatment with KH550 solution, the organic functional groups grafted onto the crumb rubber can react with the asphalt to produce stable covalent bonds, which can significantly improve the performance of asphalt rubber. However, as the crumb rubber can never be completely dissolved in the asphalt, the location of the crumb rubber is prone to stress concentration during the low-temperature stressing process, resulting in premature damage to the specimen.

3.3. Test Results of the Temperature Sensitivity. A penetration index, PI, was used to evaluate the temperature sensitivity of the modified asphalt rubber. The bigger the PI value, the lower the temperature sensitivity of the asphalt, that is, the better its temperature sensitivity performance. The PI value was calculated from penetration tests conducted at $15^{\circ} \mathrm{C}$, $25^{\circ} \mathrm{C}$, and $30^{\circ} \mathrm{C}$. The results are shown in Table 5 .

Table 5 shows that as the KH550 concentration increased, the PI value also increased, which indicates that KH550 improves the surface properties of the crumb rubber, improving the elasticity and thixotropy of the asphalt rubber, transforming it from sol-type to gel-type, enhancing its compatibility with the asphalt and thereby reducing and significantly improving the temperature sensitivity of the modified asphalt rubber.

3.4. Test Results of the Storage Stability Performance. Storage stability performance tests confirmed the compatibility between the crumb rubber modifier treated with KH550 and the asphalt. The results are shown in Table 6.

Table 6 shows that the difference in softening point for the original asphalt rubber $\mathrm{MAR}_{0}$ was $6.9^{\circ} \mathrm{C}$, which is much larger than the $2.5^{\circ} \mathrm{C}$ maximum specified in JTG F40-2004 [23]. As the KH500 concentration increased, the softening point difference of the modified asphalt rubber gradually decreased. The main reason is that the crumb rubber and asphalt undergo a complex physical and chemical reaction at the high temperature. Although some of the crumb rubbers swell after the reacting with asphalt, they cannot be completely dissolved in asphalt. During the storage process of the asphalt rubber, segregation occurs under the action of gravity, which affects the storage stability of asphalt rubber. After the surface treatment with KH550, the surface of the crumb rubber is grafted with functional groups that react with inorganic and organic substances, which can react with inorganic and organic substances in asphalt and form stable covalent bonds, promoting the compatibility and crosslinking of crumb rubber and asphalt, enhancing the stability 
TABle 5: Asphalt rubber PI index.

\begin{tabular}{lcccc}
\hline \multirow{2}{*}{ Modified asphalt rubber } & \multicolumn{2}{c}{ Penetration $/(0.1 \mathrm{~mm})$} & $3{ }^{\circ} \mathrm{C}$ & PI index \\
\hline $\mathrm{MAR}_{0}$ & $15^{\circ} \mathrm{C}$ & $25^{\circ} \mathrm{C}$ & 54.3 & 1.95 \\
$\mathrm{MAR}_{0.7}$ & 18.9 & 35.8 & 52.0 & 2.07 \\
$\mathrm{MAR}_{1.0}$ & 18.4 & 34.5 & 51.2 & 2.17 \\
$\mathrm{MAR}_{1.3}$ & 18.3 & 33.5 & 49.2 & 2.26 \\
\hline
\end{tabular}

TABLE 6: Asphalt rubber segregation test results.

\begin{tabular}{|c|c|c|c|}
\hline \multirow{2}{*}{ Modified asphalt rubber } & \multicolumn{3}{|c|}{ Softening point $/{ }^{\circ} \mathrm{C}$} \\
\hline & Upper & Lower & Difference \\
\hline $\mathrm{MAR}_{0}$ & 68.8 & 75.7 & 6.9 \\
\hline $\mathrm{MAR}_{0.7}$ & 75.2 & 77.8 & 2.6 \\
\hline $\mathrm{MAR}_{1.0}$ & 78.1 & 79.9 & 1.8 \\
\hline $\mathrm{MAR}_{1.3}$ & 79.3 & 81.0 & 1.7 \\
\hline
\end{tabular}

of asphalt rubber, reducing the generation of segregation at the high temperature, and improving the storage stability of asphalt rubber.

According to the high-temperature test, low-temperature test, temperature sensitivity test, and segregation and dispersion performance test, the optimum concentration of KH550 pretreated crumb rubber is about $1.0 \%$.

3.5. Test Results of the Scanning Electron Microscopy. In order to study the surface modification effects of KH550 on the crumb rubber, scanning electron microscopy (SEM) was used to examine and compare the surface characteristics of ordinary crumb rubber and modified crumb rubber. The SEM results are shown in Figure 4.

The following can be seen from Figure 4.

After treating the surface with KH550, the crumb rubber was noticeably changed, with a prismatic rather than a smooth surface, indicating that the coupling groups in the KH550 reacted with the crumb rubber surface, forming stable chemical bonds and changing the previously disconnected surface to a continuous surface.

A silane coupling film was formed on the surface of the modified crumb rubber. This film can form a solid chemical bond with the black carbon in the crumb rubber, also helping to connect the crumb rubber with the asphalt to form a stable continuous system.

The surface properties of the crumb rubber were significantly changed after treatment. At a high temperature, the silane coupling film in the crumb rubber has a strong reaction with the asphalt and forms a stable structure. This can improve the performance of the asphalt rubber in relation to high temperatures, temperature sensitivity, storage stability, and segregation. The low-temperature performance of the modified crumb rubber, however, is limited because of the slowing down of intermolecular activity.

3.6. Test Results of the Infrared Spectrum. Changes in the configuration and functional groups of the modified asphalt rubber were analyzed by comparing it with the original asphalt rubber using infrared spectroscopy. The location of the infrared spectral band of the asphalt rubber and its attributions are shown in Table 7 . The results are shown in Figure 5 .

The following can be seen from Figure 5.

The saturated $\mathrm{C}-\mathrm{H}$ bond in the main absorption peak of the modified asphalt rubber was significantly lower than it was in the original asphalt rubber. This shows where the saturated $\mathrm{C}-\mathrm{H}$ bond breaks to form an unsaturated bond. It therefore appears to be the case that the strong chemical reaction between the modified crumb rubber modifier and the asphalt is more productive of breaks in chemical bonds and the formation of other stable chemical bonds. This makes the bonding between the modified crumb rubber and the asphalt better and increases its capacitance.

The treatment applied to the modified asphalt rubber increased the $\mathrm{C} \equiv \equiv \mathrm{C}$ bond vibration zone. So, the treated crumb rubber and the asphalt had greater internal crosslinking, leading to the further formation of chemical bonds. This improved the compatibility of the two materials, resulting in an increase of viscosity at high temperatures.

The increase in the methylene $\mathrm{C}$ - $\mathrm{H}$ bond shear vibration absorption peak for the modified asphalt rubber indicates that the internal crosslinking of the treated crumb rubber decreased while the reaction with the asphalt increased, promoting bonding and further reaction between the treated crumb rubber and the asphalt. This resulted in a reduction in the degree of segregation.

3.7. Comparative Road Performance Analysis. At present, SBS modified asphalt is the most widely used product for high-grade highways. This kind of asphalt generally performs well, but it has high production costs, so it is difficult to justify its use for lower-grade roads or ones where there is high traffic volume. The treated crumb rubber in modified asphalt rubber can improve the road performance of asphalt and has a very broad range of possible applications. To undertake a cost-benefit analysis of using modified asphalt rubber, 20\% modified asphalt rubber (with a KH550 concentration of $1.0 \%$ ) and $4.5 \%$ SBS modified asphalt (the 


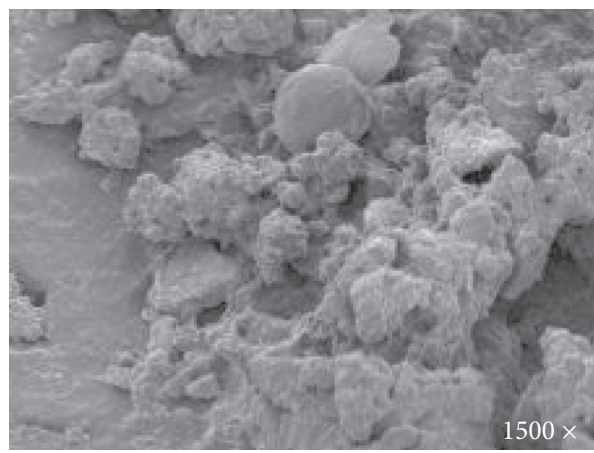

(a)

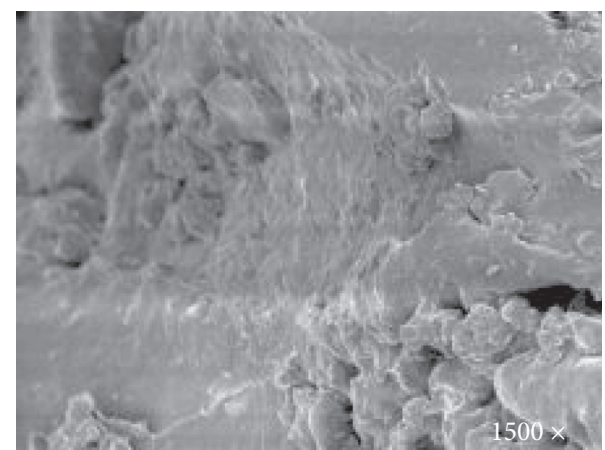

(b)

FIGURE 4: SEM photos of ordinary and modified crumb rubber: (a) ordinary crumb rubber (1500x); (b) modified crumb rubber (1500x).

TABLE 7: The asphalt rubber's position and home form in the infrared spectrum.

\begin{tabular}{|c|c|}
\hline Absorption peak & Absorption peak position $/ \mathrm{cm}^{-1}$ \\
\hline Saturated $\mathrm{C}-\mathrm{H}$ bond stretching vibration & 2924 \\
\hline $\mathrm{C}==\mathrm{C}$ bond stretching vibration & 1599 \\
\hline Methylene $\mathrm{C}-\mathrm{H}$ bond shear vibration & 1458 \\
\hline $\mathrm{C} \equiv \equiv \mathrm{C}$ bond vibration area & 2360 \\
\hline
\end{tabular}

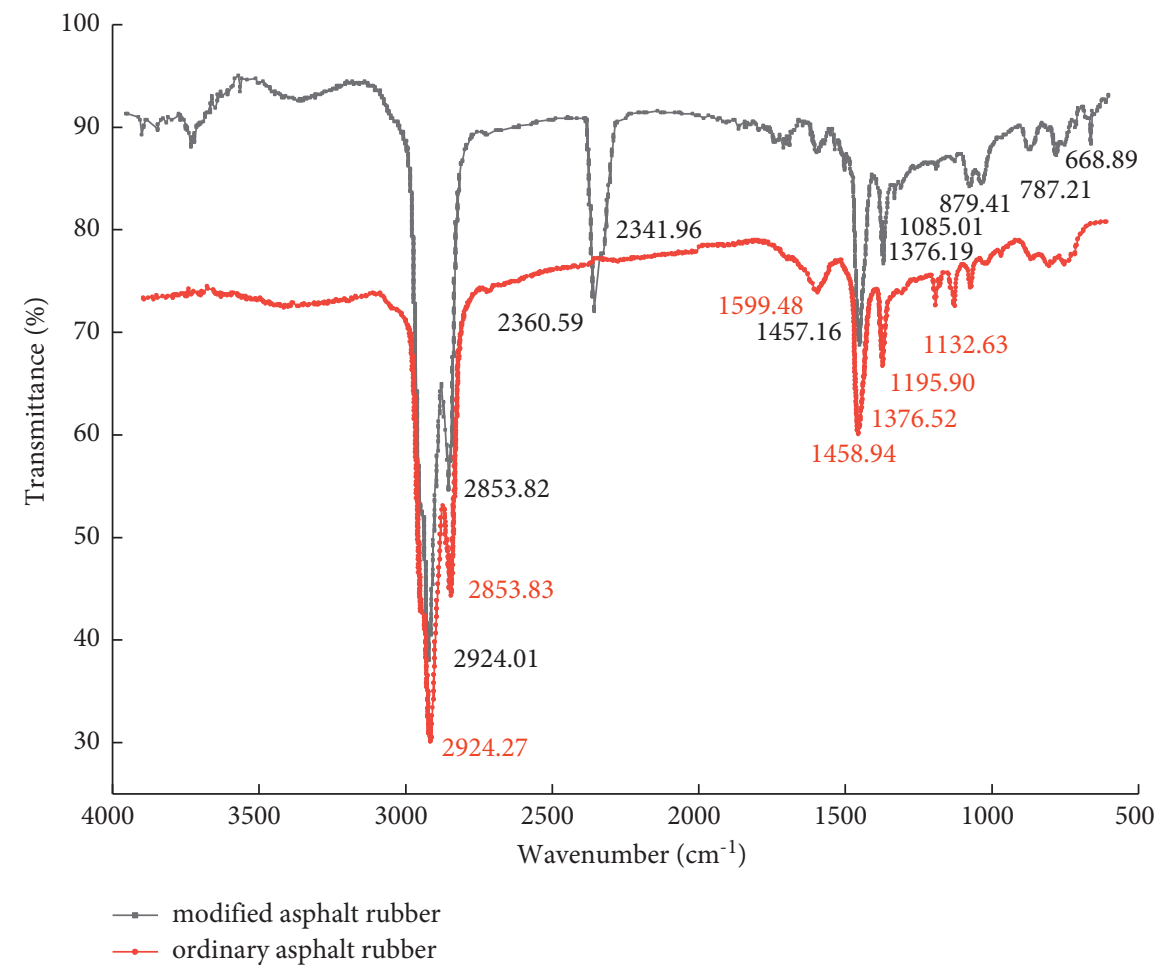

Figure 5: Infrared spectrum test results.

current content for SBG modified asphalt is generally between $4.0 \%$ and $5.0 \%$ ) were subjected to a cost comparison. A comparison of the performance indices of the two types of modified asphalt is shown in Table 8. The results of the economic benefit comparison are shown in Table 9.

Table 8 shows that after surface modification by KH550, the high-temperature performance of the crumb rubber modifier was significantly improved, with its performance index exceeding that of SBS modified asphalt. Although the low-temperature ductility of the crumb rubber modifier was clearly lower than that of SBS modified asphalt, according to recent research, the presence of crumb rubber modifier particles in asphalt rubber can make it easier for a concentration of stress to occur during tensile processes, 
TABLE 8: Comparison of the performance indices of modified asphalt rubber and SBS modified asphalt.

\begin{tabular}{lcc}
\hline Performance index & Modified asphalt rubber & SBS modified asphalt \\
\hline Penetration $\left(25^{\circ} \mathrm{C}, 100 \mathrm{~g}, 5 \mathrm{~s}\right) /(0.1 \mathrm{~mm})$ & 33.5 & 51.4 \\
Ductility $\left(5^{\circ} \mathrm{C}, 5 \mathrm{~cm} \cdot \mathrm{min}^{-1}\right)(\mathrm{cm})$ & 10.6 & 25.8 \\
Softening point $(\mathrm{R} \& \mathrm{~B})(\mathrm{C})$ & 79.3 & 76.1 \\
Elastic restitution $\left(25^{\circ} \mathrm{C}\right)(\%)$ & 85 & 87 \\
PG standard & PG82-28 & PG76-28 \\
\hline
\end{tabular}

Table 9: Analysis of the economic benefit of modified asphalt rubber.

\begin{tabular}{|c|c|c|c|c|c|c|c|}
\hline \multirow{2}{*}{$\begin{array}{l}\text { Asphalt type } \\
\text { Raw material }\end{array}$} & \multicolumn{5}{|c|}{ Modified asphalt rubber } & \multicolumn{2}{|c|}{ SBS modified asphalt } \\
\hline & $70^{\#}$ asphalt & CRM & KH550 & Water & Ethanol & $70^{\#}$ asphalt & SBS \\
\hline Proportion $(\mathrm{t})$ & 1.000 & 0.200 & 0.002 & 0.002 & 0.040 & 1.000 & 0.045 \\
\hline Unit price $/\left(\mathrm{CHY} \cdot \mathrm{t}^{-1}\right)$ & 3200 & 2800 & 38000 & 3 & 850 & 3200 & 18000 \\
\hline Material price/CHY & 3200.000 & 560.000 & 76.000 & 0.006 & 34.000 & 3200.000 & 810.000 \\
\hline Material mass $(\mathrm{t})$ & & & 1.200 & & & & \\
\hline Total material price/CHY & & & 3870 & & & & \\
\hline Price per ton/CHY & & & 3225 & & & & \\
\hline Processing price $/\left(\mathrm{CHY} \cdot \mathrm{t}^{-1}\right)$ & & & 350 & & & & \\
\hline Finished product price $/\left(\mathrm{CHY} \cdot \mathrm{t}^{-1}\right)$ & & & 3575 & & & & \\
\hline
\end{tabular}

affecting test results. In addition, the low-temperature PG standard for modified asphalt rubber and SBS modified asphalt is the same, indicating that their low-temperature performance is similar.

Table 9 shows that the product price of modified asphalt rubber is $462 \mathrm{CHY} \cdot \mathrm{t}^{-1}(12.9 \%)$ lower than that of SBS modified asphalt. In the production process, only needing a device to treat the surface of the crumb rubber can produce obvious economic benefits. In addition, the preparation of modified asphalt rubber using just a surface treatment of the crumb rubber can also reduce the amount of solid waste pollution. This has resulted in the process receiving extensive support from the state in terms of both investment and policy, with what promises to be good economic and social outcomes.

\section{Conclusions}

The consumption of crumb rubber, as a processed product of waste tires, can deal with the problem that crumb rubber is difficult to handle in the natural environment, and also by adding crumb rubber to asphalt, modified asphalt rubber can be prepared, which improves the performance of asphalt pavement. The paper uses KH550 solution to pretreat the surface of crumb rubber and prepare the modified asphalt rubber. Through a series of tests to study the performance of coupled surface modified asphalt rubber, the main conclusions were as follows.

As the concentration of KH550 solution increases, the softening point and viscosity of the modified asphalt rubber show a rising trend, with small changes in $5^{\circ} \mathrm{C}$ ductility and bending stiffness modulus $S$ and $m$, indicating that KH550 solution can improve the high-temperature performance of asphalt rubber, while KH550 solution has little effect on the low-temperature performance of asphalt rubber.

After the surface pretreatment of the crumb rubber with KH550 solution, the penetration index PI of the modified asphalt rubber gradually increases and the softening point difference gradually decreases, indicating that the pretreatment of the crumb rubber with KH550 solution can promote the compatibility of the crumb rubber and asphalt and enhance the temperature sensitivity and storage stability of the asphalt rubber.

Through high-temperature performance test, low-temperature performance test, temperature sensitivity test, and segregation performance test, the optimum concentration of KH550 for the surface treatment of crumb rubber was determined to be $1.0 \%$.

The results of the scanning electron microscope test show that KH550 solution reacts with the crumb rubber and forms a silane coupling film on the surface of the crumb rubber, which can promote the chemical reaction between the crumb rubber asphalt to form a stable structure.

The results of infrared spectroscopy tests showed that the reaction between $\mathrm{KH} 550$ surface pretreatment and the crumb rubber and asphalt resulted in a new $\mathrm{C} \equiv \mathrm{C}$ bond, which promoted the crosslinking and compatibility of the crumb rubber with the asphalt and enhanced the performance of the asphalt rubber.

\section{Data Availability}

The data used to support the findings of this study are available from the corresponding author upon request.

\section{Conflicts of Interest}

The authors declare that there are no conflicts of interest regarding the publication of this paper.

\section{Acknowledgments}

This work was supported by National Key R\&D Program Projects of China (2018YFB1600200); Natural Science 
Foundation of Hunan Province (2020JJ5578); Excellent Youth Project of Education Department of Hunan Province (20B033); Open Fund (kfj180101) of the National Engineering Laboratory of Highway Maintenance Technology (Changsha University of Science and Technology); and Foundation for Application of Steel Slag and Nickle Slag in Highway of Coastal Area (KJ-2020ZU01XM-001).

\section{References}

[1] X. Yang, Z. You, D. Perram et al., "Emission analysis of recycled tire rubber modified asphalt in hot and warm mix conditions," Journal of Hazardous Materials, vol. 365, pp. 942-951, 2019.

[2] J. Tang, C. Zhu, H. Zhang, G. Xu, F. Xiao, and S. Amirkhanian, "Effect of liquid ASAs on the rheological properties of crumb rubber modified asphalt," Construction and Building Materials, vol. 194, pp. 238-246, 2019.

[3] P. Li, X. Jiang, Z. Ding, J. Zhao, and M. Shen, "Analysis of viscosity and composition properties for crumb rubber modified asphalt," Construction and Building Materials, vol. 169, pp. 638-647, 2019.

[4] A. P. Vilela, D. W. Silva, L. M. Mendes, M. A. Martins, L. E. V. D. B. Vaz, and R. F. Mendes, "Surface modification of tire rubber waste by air plasma for application in wood-cement panels," Bioresources, vol. 13, pp. 6409-6427, 2018.

[5] X. Ding, T. Ma, W. Zhang, and D. Zhang, "Experimental study of stable crumb rubber asphalt and asphalt mixture," Construction and Building Materials, vol. 157, pp. 975-981, 2017.

[6] Z. Chen, J. Pei, T. Wang, and S. Amirkhanian, "High temperature rheological characteristics of activated crumb rubber modified asphalts," Construction and Building Materials, vol. 194, pp. 122-131, 2019.

[7] M. Bueno, J. Luong, F. Terán, U. Viñuela, and S. E. Paje, "Macrotexture influence on vibrational mechanisms of the tyre-road noise of an asphalt rubber pavement," International Journal of Pavement Engineering, vol. 15, no. 7, pp. 606-613, 2014.

[8] L. Liu, Z. H. Liu, C. C. Yang, H. You, and W. Li, "Effect of the binary compound method of TOR promoting dissolution and $\mathrm{NaOH}$ solution surface treatment on the performance of rubber asphalt," Construction and Building Materials, vol. 305, 2021.

[9] Z. Ding, J. Jiang, S. Y. He, and C. Shen, "Research on physical and chemical behavior of crumb rubber in asphalt rubber," Advanced Materials Research, vol. 255-260, pp. 3411-3415, 2011.

[10] K. Egami, M. Kimura, and T. Hamaguchi, "Effect of crumb rubber modifier dissolution on storage stability of crumb rubber-modified asphalt," Transportation Research Record Journal of the Transportation Research Board, vol. 2370, pp. 109-115, 2013.

[11] A. Ghavibazoo, M. Abdelrahman, and M. Ragab, "Changes in composition and molecular structure of asphalt in mixing with crumb rubber modifier," Road Materials and Pavement Design, vol. 17, pp. 1-14, 2016.

[12] M. Provost, K. Raulin, T. Maindron, and V. Gaud, "Influence of silane coupling agent on the properties of UV curable SiO2PMMA hybrid nanocomposite," Journal of Sol-Gel Science and Technology, vol. 89, no. 3, pp. 796-806, 2019.

[13] Z. Li, J. Wan, Y. Li, Y. Li, F. Zhao, and S. Zhao, "Effects of coupling agents on the properties of an NR/SBR matrix and its adhesion to continuous basalt fiber cords," Journal of Applied Polymer Science, vol. 136, no. 8, Article ID 47098, 2019.

[14] J. Song, M. Xu, W. Liu et al., "Thermoplastic rubber (TPR) modified by a silane coupling agent and its influence on the mechanical properties of oil well cement pastes," Advances in Materials Science and Engineering, vol. 2019, Article ID 3587081, 11 pages, 2019.

[15] M. Raj, S. Joshi, R. Savaliya, and L. Raj, "Studies on the effects of cenosphere on polypropylene matrix using silane coupling agent," Journal of Thermoplastic Composite Materials, vol. 31, no. 11, pp. 1510-1528, 2018.

[16] Z. Wang, Y. Liu, H. Lv, and B. Yang, "Enhancement of interface performance between shape memory alloy fiber and polymer matrix using silane coupling agent KH550 and Al2 O3 nanoparticles," Polymer Composites, vol. 39, no. 9, pp. 3040-3047, 2018.

[17] W. K. Choi, G. Y. Park, B. S. Kim, and M. K. Seo, "Effect of silane coupling agent on the creep behavior and mechanical properties of carbon fibers/acrylonitrile butadiene rubber composites," Journal of Nanoscience and Nanotechnology, vol. 18, no. 9, pp. 6220-6227, 2018.

[18] Y. Xiang, Y. Xie, and G. Long, "Effect of basalt fiber surface silane coupling agent coating on fiber-reinforced asphalt: from macro-mechanical performance to micro-interfacial mechanism," Construction and Building Materials, vol. 179, pp. 107-116, 2018.

[19] Q. Wei and W. H. Wang, "Properties of phenol formaldehyde resin modified with silane coupling agent (KH550)," International Journal of Adhesion and Adhesives, vol. 84, pp. 166-172, 2018.

[20] AASHTO T315-05, Standard Method of Test for Determining the Rheological Properties of Asphalt Binder Using a Dynamic Shear Rheometer, American Association of State Highway and Transportation Officials, Washington, DC, USA, 2005.

[21] AASHTO T313-12, Determining the Flexural Creep Stiffness of Asphalt Binder Using the Bending Beam Rheometer (BBR), American Association of State Highway and Transportation Officials, Washington, DC, USA, 2012.

[22] China, MoT.PsRo, Standard Test Methods of Bitumen and Bituminous Mixtures for Highway Engineering, JTG E20-2011, China Communications Press Co., Ltd., Beijing, China, 2011.

[23] China, MoT.PsRo, Technical Specifications for Construction Highway Asphalt Pavement. JTG F40-2004, China Communications Press Co., Ltd., Beijing, China, 2004. 